\title{
Metformin-Associated Lactic Acidosis following Intentional Overdose Successfully Treated with Tris-Hydroxymethyl Aminomethane and Renal Replacement Therapy
}

\author{
Ngan Lam, ${ }^{1,2}$ Gurbir Sekhon, ${ }^{3}$ and Andrew A. House ${ }^{1,3}$ \\ ${ }^{1}$ Division of Nephrology, Department of Medicine, Western University, London, ON, Canada N6A 3K7 \\ ${ }^{2}$ London Health Sciences Centre, Kidney Clinical Research Unit, Victoria Hospital, Westminster Tower 800 Commissioners Road East, \\ London, ON, Canada N6A 4G5 \\ ${ }^{3}$ Department of Medicine, Western University, London, ON, Canada N6A $3 K 7$
}

Correspondence should be addressed to Ngan Lam,nlam5@uwo.ca

Received 19 February 2012; Accepted 6 May 2012

Academic Editors: Y. Fujigaki, D. Packham, A. Papagianni, and H. Schiffl

Copyright (C) 2012 Ngan Lam et al. This is an open access article distributed under the Creative Commons Attribution License, which permits unrestricted use, distribution, and reproduction in any medium, provided the original work is properly cited.

\begin{abstract}
A 43-year-old woman was brought to the hospital with severe metabolic acidosis ( $\mathrm{pH} \mathrm{6.56}$, bicarbonate 3 mmol/L, and lactate $18.4 \mathrm{mmol} / \mathrm{L}$ ) and a serum creatinine of $162 \mu \mathrm{mol} / \mathrm{L}$ with a serum potassium of $7.8 \mathrm{mmol} / \mathrm{L}$. A delayed diagnosis of metforminassociated lactic acidosis was made, and she was treated with tris-hydroxymethyl aminomethane (THAM) and renal replacement therapy (RRT). Following a complete recovery, she admitted to ingesting 180 tablets (90 grams) of metformin. Her peak serum metformin concentration was $170 \mu \mathrm{g} / \mathrm{mL}$ (therapeutic range $1-2 \mu \mathrm{g} / \mathrm{mL}$ ). Our case demonstrates an intentional metformin overdose resulting in lactic acidosis in a nondiabetic patient who was successfully treated with THAM and RRT.
\end{abstract}

\section{Background}

Metformin is an oral antihyperglycemic agent that is the first-line therapy for noninsulin-dependent diabetes mellitus [1]. Although the adverse event rate is $20-30 \%$, the majority of these are gastrointestinal symptoms such as abdominal pain and nausea [2]. Metformin has been associated with an increased risk of lactic acidosis through the inhibition of hepatic gluconeogenesis causing an increased level of lactate, pyruvate, and alanine. The incidence of metforminassociated lactic acidosis (MALA) is reported to be 3 per 100,000 person-years [3]. The symptoms of severe MALA can be nonspecific, such as tachycardia, hypotension, tachypnea, and mental status changes, potentially misleading the diagnosis and delaying treatment.

\section{Case Report}

A 43-year-old woman was brought to the emergency room complaining of chest pain for 20 hours radiating to her back. Her medical history was significant for hypertension for which she was on atenolol $50 \mathrm{mg}$ daily and anxiety for which she was on mirtazapine $30 \mathrm{mg}$ daily and lorazepam 2 mg three times a day.

Her temperature was $32.3^{\circ} \mathrm{C}$ (axilla), blood pressure $66 / 45 \mathrm{mmHg}$, heart rate 57 beats per minute, and oxygen saturation $97 \%$ on 3 liters. Her respiratory, cardiac, and abdominal exams were unremarkable. In addition to normal cardiac enzymes, her initial laboratory values revealed the following: serum creatinine $162 \mu \mathrm{mol} / \mathrm{L}$, potassium $5.3 \mathrm{mmol} / \mathrm{L}$, bicarbonate $4 \mathrm{mmol} / \mathrm{L}$, anion gap $31 \mathrm{mmol} / \mathrm{L}$, lactate $18.4 \mathrm{mmol} / \mathrm{L}$, osmolar gap $18.3 \mathrm{mOsm} / \mathrm{kg}$, venous blood gas: $\mathrm{pH}$ 6.56, pCO2 $35 \mathrm{mmHg}$, bicarbonate $3 \mathrm{mmol} / \mathrm{L}$ (Table 1). Four hours after she first arrived, her condition rapidly deteriorated, and she became obtunded requiring intubation and transfer to the intensive care unit (ICU).

Prior to intubation, the patient adamantly denied any toxic ingestion. She was treated with levofloxacin and piperacillin/tazobactam for potential sepsis. Her acidosis was treated with sodium bicarbonate infusion. Passive external rewarming therapy was used to treat her 
TABLE 1: Laboratory investigations.

\begin{tabular}{|c|c|c|c|c|c|}
\hline Results & Initial & 4 hours after arrival & 6 hours after arrival & $\begin{array}{c}10 \text { hours after arrival } \\
\text { (before RRT) }\end{array}$ & Final (after RRT) \\
\hline Arterial pH & 6.83 & 6.92 & 6.82 & 7.01 & 7.43 \\
\hline Arterial bicarbonate $(\mathrm{mmol} / \mathrm{L})$ & 3 & 4 & 3 & 4 & 31 \\
\hline Arterial $\mathrm{pCO}_{2}(\mathrm{mmHg})$ & 20 & 18 & 18 & 16 & 47 \\
\hline Sodium (mmol/L) & 145 & 146 & 145 & 153 & 139 \\
\hline Potassium $(\mathrm{mmol} / \mathrm{L})$ & 5.3 & 7.5 & 7.7 & 6.5 & 3.5 \\
\hline Chloride $(\mathrm{mmol} / \mathrm{L}$ & 110 & 114 & 110 & 107 & 104 \\
\hline Bicarbonate (mmol/L) & 4 & 4 & 3 & 3 & 24 \\
\hline Anion gap $(\mathrm{mmol} / \mathrm{L})$ & 31 & 28 & 32 & 43 & 11 \\
\hline Urea $(\mathrm{mmol} / \mathrm{L})$ & 1.9 & 2 & 2.2 & 2.6 & 6.1 \\
\hline Serum creatinine $(\mu \mathrm{mol} / \mathrm{L})$ & 162 & 158 & 159 & 162 & 61 \\
\hline Albumin $(\mathrm{g} / \mathrm{L})$ & 31 & 36 & 33 & 35 & - \\
\hline Plasma glucose $(\mathrm{mmol} / \mathrm{L})$ & 7.8 & 1.2 & 8.5 & 3.9 & 8 \\
\hline Serum osmolality (mOsm/kg) & 318 & - & 330 & - & - \\
\hline Osmolar gap (mOsm/kg) & 18.3 & - & 29.3 & - & - \\
\hline Leukocytes $\left(\times 10^{9} / \mathrm{L}\right)$ & 26.8 & 27.3 & 34.1 & 28.7 & 11.9 \\
\hline Creatine kinase $(\mathrm{U} / \mathrm{L})$ & 87 & 77 & - & - & - \\
\hline Troponin-T $(\mu \mathrm{g} / \mathrm{L})$ & $<0.01$ & $<0.01$ & - & - & - \\
\hline Alanine aminotransferase (U/L) & - & 80 & 110 & 127 & 77 \\
\hline $\begin{array}{l}\text { Aspartate aminotransferase } \\
(\mathrm{U} / \mathrm{L})\end{array}$ & - & 77 & 108 & 124 & 62 \\
\hline Alkaline phosphatase (U/L) & - & 71 & 69 & 65 & 66 \\
\hline
\end{tabular}

$\mathrm{pCO}_{2}$ : pressure of carbon dioxide, $\mathrm{pH}$ : potential hydrogen, RRT: renal replacement therapy.

hypothermia. Her hypotension required isotonic intravenous fluids and vasopressor agents including phenylephrine, norepinephrine, dobutamine, and vasopressin. Cardiovascular/thoracic surgery was consulted to rule out aortic dissection, and a transesophageal echocardiogram was inconclusive. The patient underwent an urgent CT thorax/abdomen/pelvis with contrast, which did not reveal an aortic dissection or abscess.

Biochemically, she continued to worsen with a peak serum potassium of $7.8 \mathrm{mmol} / \mathrm{L}$ treated with calcium chloride, calcium gluconate, and kayexalate. She became hypoglycemic with a nadir blood sugar of $1.2 \mathrm{mmol} / \mathrm{L}$ treated with dextrose intravenously. Her anion gap rose to $43 \mathrm{mmol} / \mathrm{L}$ and her peak osmolar gap was $29.3 \mathrm{mOsm} / \mathrm{kg}$. Her urine toxicology screen was positive for opiates and benzodiazepines but negative for cannabis, cocaine, amphetamine, and barbiturates. Her serum acetaminophen level was $81 \mu \mathrm{mol} / \mathrm{L}$ but the remainder of her serum toxicology screen was negative for tricyclics, salicylates, ethanol, methanol, isopropanol, acetone, and ethylene glycol.

The patient's hospital chart arrived to the ICU where it was discovered that the patient had a history of a suicide attempt by overdose 15 years prior. It was also discovered that a family member had diabetes treated with metformin. A diagnosis of metformin-associated lactic acidosis by intentional overdose was made.

Nephrology was consulted and a temporary internal jugular hemodialysis (HD) catheter was inserted. The patient was treated with 6 hours of HD starting 12 hours after her initial arrival to the hospital. She was also started on tris-hydroxymethyl aminomethane (THAM, $0.3 \mathrm{mmol} / \mathrm{L}$, $36 \mathrm{mg} / \mathrm{mL}, 1600 \mathrm{mg}$ administered by infusion at $300 \mathrm{~mL} / \mathrm{hr}$ for 5 hours) to buffer the lactic acid given the preservation of her urine output, which was maintained at approximately $200 \mathrm{~mL} / \mathrm{hr}$. Given her initial level of acetaminophen and a rise in her liver enzymes, she was treated with $\mathrm{N}$ acetylcysteine (NAC) for a possible missed acetaminophen overdose.

The patient received one 8-hour session of continuous veno-venous hemofiltration (CVVHF) the next day for ongoing metabolic acidosis. Her condition dramatically improved, and she was extubated the following day. Her renal function returned to baseline and she did not require any further renal replacement therapy (RRT). She admitted to taking 180 tablets (500 mg each, 90 grams total) of metformin. Her peak serum metformin level, taken almost 8 hours after her arrival to the hospital, was $170 \mu \mathrm{g} / \mathrm{mL}$ (therapeutic range $1-2 \mu \mathrm{g} / \mathrm{mL}$ ).

\section{Discussion}

A recent Cochrane review demonstrated that in patients with type 2 diabetes, who were using metformin therapeutically, there were no cases of fatal or nonfatal lactic acidosis nor was there an increased risk of elevated lactate compared with other anti-hyperglycemic agents [24]. This review did 





not apply to intentional metformin overdose for which the literature is limited and single case reports continue to be published (Table 2) [4-23]. Intentional overdoses involving healthy individuals with no history of diabetes are even more rare $[4,6,10,15,17,19,21]$. In the majority of cases, the diagnosis is obvious based on patient and collateral history, and treatment is initiated in a timely fashion.

The initial management of MALA is supportive and may include gastrointestinal decontamination if the ingestion was recent and no contraindications are present. Further treatment options include intravenous hydration, sodium bicarbonate, dextrose for hypoglycemia, intubation for airway protection, and mechanical ventilation for respiratory failure, vasopressor support and RRT. The role of RRT appears to be in the correction of the acidosis as opposed to the clearance of metformin, although some limited clearance can occur [20,23]. Various forms of dialysis, either alone or in combination, have been used to treat MALA, including intermittent HD [4-9, 11-15, 17, 19, 21], hemoperfusion (HP) [12], CVVHF $[9,11,13,20]$, continuous veno-venous hemodialysis (CVVHD) $[15,22,23]$, continuous venovenous hemodiafiltration (CVVHDF) $[5,15,16]$, and plasma exchange (PLEX) [8], all with varying outcomes. In some cases, RRT is not utilized if the degree of acidosis or acute kidney injury is not severe or the patient is not acutely ill $[10,18,25]$.

The role of sodium bicarbonate in the treatment of MALA is widely debated and controversial. Sodium bicarbonate may deliver an unwanted sodium load resulting in hypervolemia. It is also a carbon dioxide producing buffer, which may decrease cardiac output [17]. THAM buffers acid without the production of excess carbon dioxide and is used as an alternative to sodium bicarbonate [26]. The hydrogenated THAM is then excreted in the urine making it less efficacious if the patient is anuric. The clinical efficacy of THAM compared with sodium bicarbonate in the treatment of severe metabolic acidosis is currently unproven.

To our knowledge, this is the first published case of MALA successfully treated with THAM and RRT. While dialysis is used in the majority of cases of MALA, we demonstrate that THAM may also have a role in alkalinization for the treatment of severe lactic acidosis associated with metformin overdose. As far as we know, our nondiabetic patient survived despite having the lowest documented $\mathrm{pH}$ at 6.56 associated with a high metformin concentration of $170 \mu \mathrm{g} / \mathrm{mL}$.

\section{Conflict of Interests}

The authors declare that they have no conflict of interests.

\section{Acknowledgments}

The authors wish to thank Dr. Richard B. Kim (Department of Medicine, Division of Clinical Pharmacology, University of Western Ontario, London, Ontario, Canada) and his laboratory staff for their assistance in measuring the patient's serum metformin level.

\section{References}

[1] D. M. Nathan, J. B. Buse, M. B. Davidson et al., "Medical management of hyperglycemia in type 2 diabetes: a consensus algorithm for the initiation and adjustment of therapy: a consensus statement of the American Diabetes Association and the European Association for the Study of Diabetes," Diabetes Care, vol. 32, no. 1, pp. 193-203, 2009.

[2] R. A. DeFronzo, "Pharmacologic therapy for type 2 diabetes mellitus," Annals of Internal Medicine, vol. 131, no. 4, pp. 281303, 1999.

[3] C. J. Bailey and R. C. Turner, "Metformin," The New England Journal of Medicine, vol. 334, no. 9, pp. 574-579, 1996.

[4] A. Rathnapala, T. Matthias, and S. Jayasinghe, "Severe lactic acidosis and acute renal failure following ingestion of metformin and kerosene oil: a case report," Journal of Medical Case Reports, vol. 6, no. 1, article 8, 2012.

[5] S. I. Rifkin, C. McFarren, R. Juvvadi, and S. S. Weinstein, "Prolonged hemodialysis for severe metformin intoxication," Renal Failure, vol. 33, no. 4, pp. 459-461, 2011.

[6] H. Akoglu, B. Akan, S. Piskinpasa et al., "Metformin-associated lactic acidosis treated with prolonged hemodialysis," American Journal of Emergency Medicine, vol. 29, no. 5, pp. 575.e3575.e5, 2011.

[7] D. M. Dell'Aglio, L. J. Perino, J. D. Todino, D. A. Algren, and B. W. Morgan, "Metformin overdose with a resultant serum $\mathrm{pH}$ of 6.59: survival without sequalae," Journal of Emergency Medicine, vol. 39, no. 1, pp. e77-e80, 2010.

[8] I. Turkcuer, B. Erdur, I. Sari, A. Yuksel, P. Tura, and S. Yuksel, "Severe metformin intoxication treated with prolonged haemodialyses and plasma exchange," European Journal of Emergency Medicine, vol. 16, no. 1, pp. 11-13, 2009.

[9] P. W. Yang, K. H. Lin, S. H. Lo, L. M. Wang, and H. D. Lin, "Successful treatment of severe lactic acidosis caused by a suicide attempt with a metformin overdose," Kaohsiung Journal of Medical Sciences, vol. 25, no. 2, pp. 93-97, 2009.

[10] T. Basturk, B. Balkan, M. Aytekin, A. Unsal, and A. Alagol, "Lactic acidosis due to metformin overdose. What treatment should be? A case report and review of the literature," BANTAO Journal, vol. 7, pp. 44-46, 2009.

[11] M. Galea, N. Jelacin, K. Bramham, and I. White, "Severe lactic acidosis and rhabdomyolysis following metformin and ramipril overdose," British Journal of Anaesthesia, vol. 98, no. 2, pp. 213-215, 2007.

[12] P. Y. F. Guo, L. J. Storsley, and S. N. Finkle, "Severe lactic acidosis treated with prolonged hemodialysis: recovery after massive overdoses of metformin," Seminars in Dialysis, vol. 19, no. 1, pp. 80-83, 2006.

[13] U. Panzer, S. Kluge, G. Kreymann, and G. Wolf, "Combination of intermittent haemodialysis and high-volume continuous haemofiltration for the treatment of severe metformininduced lactic acidosis," Nephrology Dialysis Transplantation, vol. 19, no. 8, pp. 2157-2158, 2004.

[14] S. Gjedde, A. Christiansen, S. B. Pedersen, and J. Rungby, "Survival following a metformin overdose of 63 g: a case report," Pharmacology and Toxicology, vol. 93, no. 2, pp. 98-99, 2003.

[15] C. T. Chang, Y. C. Chen, J. T. Fang, and C. C. Huang, "High anion gap metabolic acidosis in suicide: don't forget metformin intoxication-two patients' experiences," Renal Failure, vol. 24, no. 5, pp. 671-675, 2002.

[16] K. F. H. Teale, A. Devine, H. Stewart, and N. J. H. Harper, “The management of metformin overdose," Anaesthesia, vol. 53, no. 7, pp. 698-701, 1998. 
[17] D. Heaney, A. Majid, and B. Junor, "Bicarbonate haemodialysis as a treatment of metformin overdose," Nephrology Dialysis Transplantation, vol. 12, no. 5, pp. 1046-1047, 1997.

[18] J. McLelland, "Recovery from metformin overdose," Diabetic Medicine, vol. 2, no. 5, pp. 410-411, 1985.

[19] J. Perrone, C. Phillips, and D. Gaieski, "Occult metformin toxicity in three patients with profound lactic acidosis," Journal of Emergency Medicine, vol. 40, no. 3, pp. 271-275, 2011.

[20] A. M. Arroyo, T. A. Walroth, J. B. Mowry, and L. W. Kao, "The MALAdy of metformin poisoning: is CVVH the cure?" American Journal of Therapeutics, vol. 17, no. 1, pp. 96-100, 2010.

[21] J. R. Suchard and T. A. Grotsky, "Fatal metformin overdose presenting with progressive hyperglycemia," Western Journal of Emergency Medicine, vol. 9, pp. 160-164, 2008.

[22] P. Nisse, M. Mathieu-Nolf, M. Deveaux, X. Forceville, and A. Combes, "A fatal case of metformin poisoning," Journal of Toxicology, vol. 41, no. 7, pp. 1035-1036, 2003.

[23] F. Barrueto, W. J. Meggs, and M. J. Barchman, "Clearance of metformin by hemofiltration in overdose," Journal of Toxicology, vol. 40, no. 2, pp. 177-180, 2002.

[24] S. R. Salpeter, E. Greyber, G. A. Pasternak, and E. E. Salpeter, "Risk of fatal and nonfatal lactic acidosis with metformin use in type 2 diabetes mellitus," Cochrane Database of Systematic Reviews, no. 2, Article ID CD002967, 2010.

[25] N. Peters, N. Jay, D. Barraud et al., "Metformin-associated lactic acidosis in an intensive care unit," Critical Care, vol. 12, no. 6, article R149, 2008.

[26] E. A. Hoste, K. Colpaert, R. C. Vanholder et al., "Sodium bicarbonate versus THAM in ICU patients with mild metabolic acidosis," Journal of Nephrology, vol. 18, no. 3, pp. 303-307, 2005. 


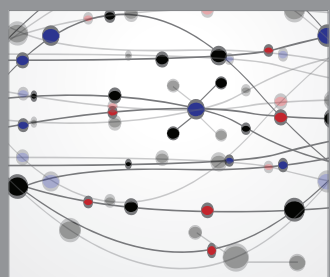

The Scientific World Journal
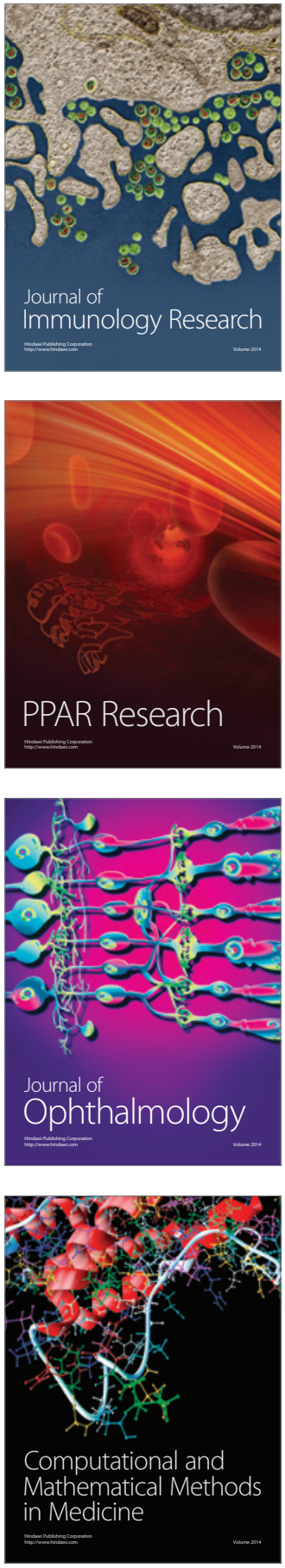

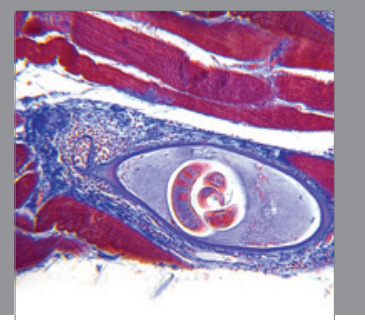

Gastroenterology

Research and Practice
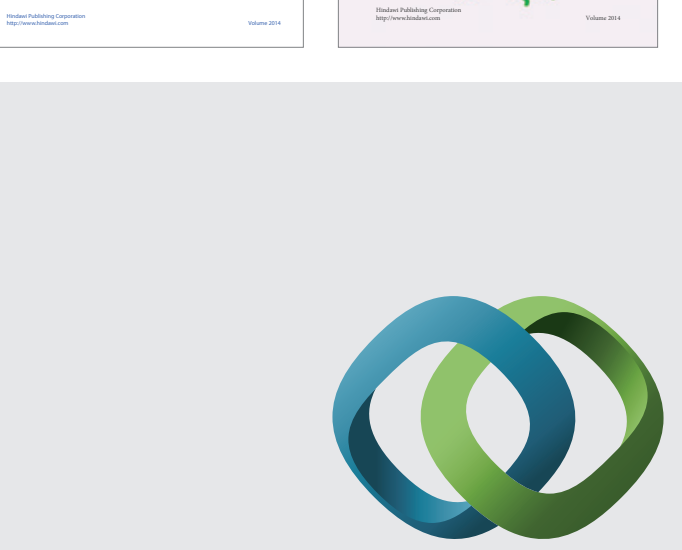

\section{Hindawi}

Submit your manuscripts at

http://www.hindawi.com
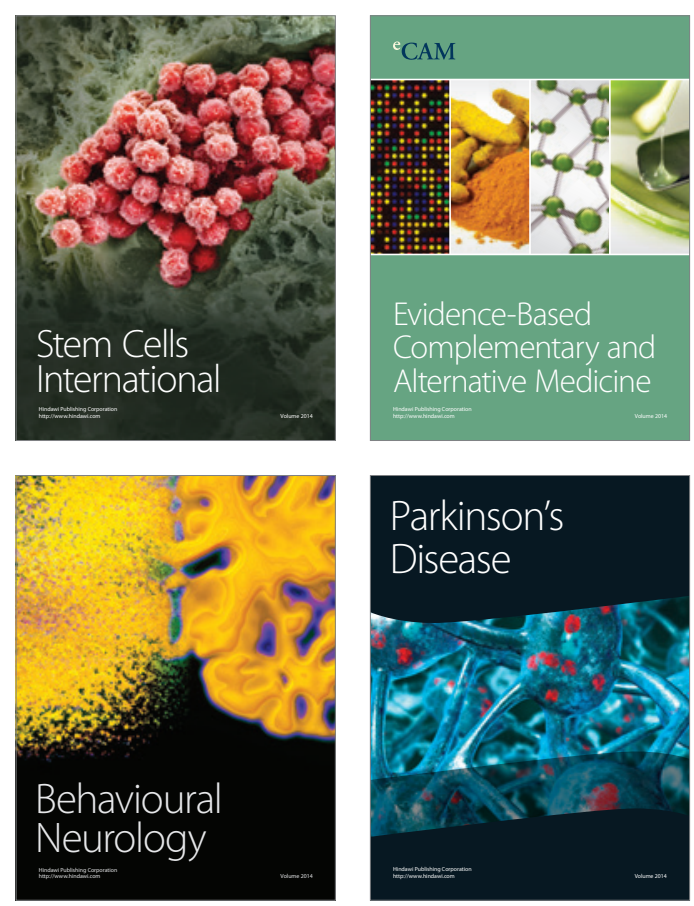

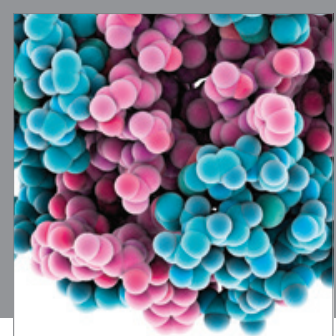

Journal of
Diabetes Research

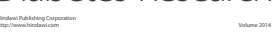



Disease Markers
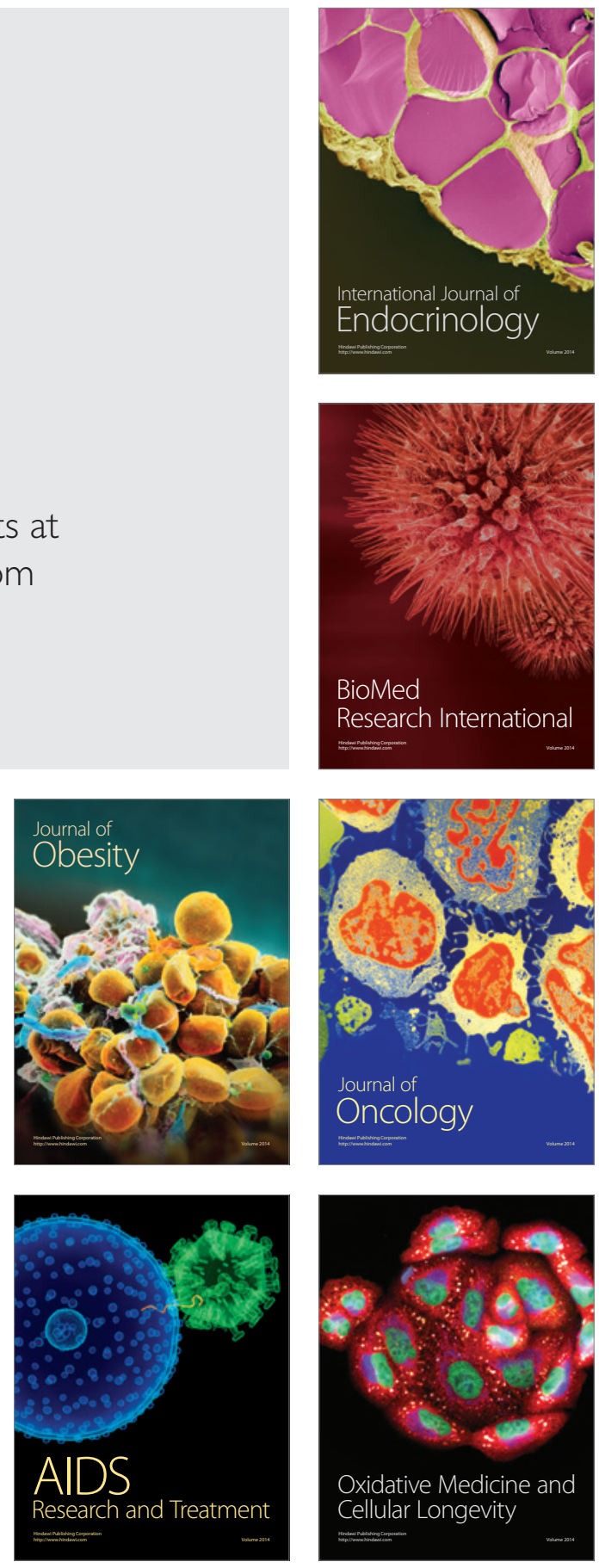